Article

\title{
Antioxidant Properties of Polysaccharide from the Brown Seaweed Sargassum graminifolium (Turn.), and Its Effects on Calcium Oxalate Crystallization
}

\section{Chao-Yan Zhang ${ }^{1,2}$, Wen-Hui Wu ${ }^{2}$, Jue Wang ${ }^{2}$ and Min-Bo Lan ${ }^{1, *}$}

1 Shanghai Key Laboratory of Functional Materials Chemistry, Research Center of Analysis and Testing, East China University of Science and Technology, Shanghai 200237, China

2 College of Food Science and Technology, Institutes of Marine Sciences, Shanghai Ocean University, Shanghai 201306, China; E-Mails: chyzhang@shou.edu.cn (C.-Y.Z.); whwu@shou.edu.cn (W.-H.W.); wangqilung@126.com (J.W.)

* Author to whom correspondence should be addressed; E-Mail: minbolan@ecust.edu.cn; Tel./Fax: +86-021-64253574.

Received: 24 November 2011; in revised form: 2 January 2012 / Accepted: 5 January 2012 / Published: 16 January 2012

\begin{abstract}
We investigated the effects of polysaccharides from the brown seaweed Sargassum graminifolium (Turn.) (SGP) on calcium oxalate crystallization, and determined its antioxidant activities. To examine the effects of SGP on calcium oxalate crystallization, we monitored nucleation and aggregation of calcium oxalate monohydrate crystals, using trisodium citrate as a positive control. We assessed antioxidant activities of SGP by determining its reducing power, its ability to scavenge superoxide radicals, and its activity in the 1,1-diphenyl-2-picrylhydrazyl (DPPH) assay. The nucleation inhibition ratio of trisodium citrate and SGP was 58.5 and $69.2 \%$, respectively, and crystal aggregation was inhibited by 71.4 and $76.8 \%$, respectively. Increasing concentrations of SGP resulted in increased scavenging of superoxide anions and DPPH radicals $\left(\mathrm{IC}_{50}=1.9\right.$ and $0.6 \mathrm{mg} / \mathrm{mL}$, respectively). These results suggest that SGP could be a candidate for treating urinary stones because of its ability to inhibit calcium oxalate crystallization and its antioxidant properties.
\end{abstract}

Keywords: calcium oxalate crystallization; antioxidant; polysaccharide; Sargassum graminifolium 


\begin{abstract}
Abbreviations
SGP, polysaccharide from Sargassum graminifolium; IR, infrared spectrum; DPPH, 1,1-diphenyl-2picrylhydrazyl free radical; Ox, oxalate; $\mathrm{CaOx}$, calcium oxalate; $\mathrm{OD}$, optical density; $\mathrm{S}_{\mathrm{N}}$, maximum increase of optical density with time; $\mathrm{S}_{\mathrm{A}}$, rate of aggregation derived from the maximum decrease in optical density; $t_{\max }$, maximum time; COM, Calcium oxalate monohydrate; COD, Calcium oxalate dehydrate; COT, Calcium oxalate trihydrate.
\end{abstract}

\title{
1. Introduction
}

In recent years, there has been much interest in isolating novel bioactive compounds with beneficial effects on human health from marine resources. Marine algae are valuable sources of structurally diverse bioactive compounds. Sulfated polysaccharides are widespread in marine algae, especially brown seaweeds. Sulfated polysaccharides show various biological activities, including anticoagulant, antioxidant, antiviral, anticancer and immunomodulating activities [1-5]. Zhang et al. [6] reported that sulfated polysaccharides play important roles as free-radical scavengers and antioxidants, which can prevent oxidative damage in living organisms. The low molecular weight polysaccharides heparin and fucoidan provided protection against oxalate (Ox)-induced oxidative renal injury [3,7]. Ox and calcium oxalate monohydrate (COM) induce the generation of free radicals, which are major mediators of the pathologic consequences of the formation of kidney stones [8]. Hence, sulfated polysaccharides may be a potential candidate for treating urinary stones because of their protective role in Ox-mediated peroxidative injury.

Urinary stones affect a large proportion of the population. Approximately $85 \%$ of urinary stones are calcium stones, which consist of $\mathrm{Ox}$ and phosphate, either alone or in combination $[9,10]$. Crystallization is a physical and chemical process in which there is a change of state from solution to solid. This involves several physicochemical events, i.e., nucleation, growth and aggregation, but the mechanisms controlling these events are not fully understood [11,12].

It is widely known that urinary stones frequently reoccur, and despite progress in medical therapies, there is no satisfactory drug for treatment of this condition [13-15]. Recent research has shown that exposure of renal cells to high concentrations of $\mathrm{Ox}$ and/or calcium oxalate $(\mathrm{CaOx})$ crystals leads to the production of reactive oxygen species (ROS) in tissue culture and animal model studies [16-18]. ROS play critical roles as signaling molecules; however, an overproduction of ROS and/or a reduction in cellular antioxidant capacities due to downregulation of antioxidant enzymes results in oxidative stress [19]. Some studies in vitro and in vivo showed that treatments with antioxidants and free-radical scavengers can reduce $\mathrm{Ox} / \mathrm{CaOx}$ crystal-induced injuries [18,20]. Some well-known antioxidants, such as vitamin E, have shown promising effects in populations of recurrent stone-formers [21]. These results suggest that there is great potential for the therapeutic application of antioxidants and free-radical scavengers to reduce the occurrence and reoccurrence of urinary stones and to provide superior renal protection [22]. Since the conventional treatment methods vary in their effectiveness, it is worth searching for alternative treatments, e.g., different diets or medicinal plants $[8,23]$ for the treatment of urinary stones. 
Brown seaweeds have been used in traditional Chinese medicine for more than 1000 years [24]. Sargassum graminifolium, a brown seaweed extensively distributed along the coasts of the South China Sea and the East China Sea, is commonly consumed as seafood, and as medical resource for its antiallergic effects [25]. To fully utilize this rich resource, it is meaningful to evaluate the polysaccharide bioactivity of $S$. graminifolium. The aim of the present study was to investigate the antioxidant properties of a polysaccharide extract from $S$. graminifolium, and to determine its ability to inhibit crystallization. These properties are useful attributes for compounds that could be used to treat urinary stones.

\section{Results and Discussion}

\subsection{Properties of $S G P$}

The results show the total sugar content is $75.68 \%$, protein content is $0.12 \%$ and sulfate is $10.13 \%$. Figure 1 shows that SGP in $3471,2900,1648$ and $1253 \mathrm{~cm}^{-1}$ are absorption peaks, they are the stretching vibration of sugar ring $\mathrm{O}-\mathrm{H}, \mathrm{C}-\mathrm{H}, \mathrm{C}=\mathrm{O}$ and $\mathrm{S}=\mathrm{O}$, so this result indicates the SGP contains high sulfate content and it is consistent with chemical analysis result.

Figure 1. IR spectra of Sargassum graminifolium (Turn.) (SGP).

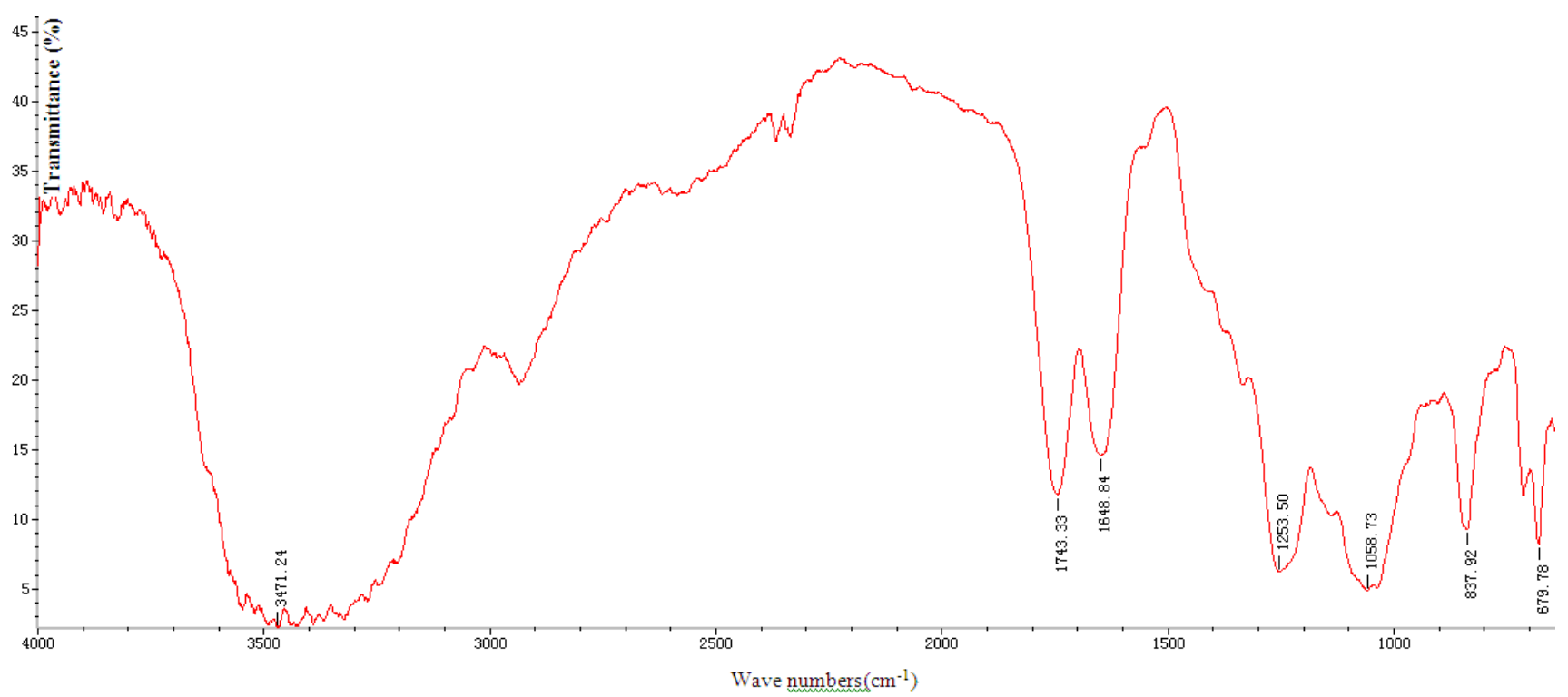

\subsection{Effect on Calcium Oxalate Crystallization}

The inhibitory effect of SGP and trisodium citrate on $\mathrm{CaOx}$ crystallization is shown in Table 1 . At concentrations of $4 \mathrm{mmol} / \mathrm{L}$ calcium and $0.5 \mathrm{mmol} / \mathrm{L} \mathrm{Ox}$, addition of $0.25 \mathrm{mmol} / \mathrm{L}$ trisodium citrate or $0.01 \mathrm{~g} / 100 \mathrm{~mL}$ SGP resulted in a nucleation percentage inhibition ratio of 58.5 and $69.2 \%$, respectively, and crystal aggregation was inhibited by 71.4 and $76.8 \%$, respectively. Compared with control conditions, both SGP and trisodium citrate significantly inhibited $\mathrm{CaOx}$ crystallization. As shown in Table 1, addition of both SGP and trisodium citrate resulted in increases in $t_{\max }$ and decreased slopes of $\mathrm{CaOx}$ crystal growth $\left(\mathrm{S}_{\mathrm{N}}\right.$ and $\left.\mathrm{S}_{\mathrm{A}}\right)(P<0.05)$. 
Table 1. Effects of SGP on calcium oxalate crystallization.

\begin{tabular}{|c|c|c|c|c|}
\hline & $\begin{array}{c}4 \mathrm{mmol} / \mathrm{L} \text { calcium} / \\
0.5 \mathrm{mmol} / \mathrm{L} \\
\text { oxalate } \\
\end{array}$ & $\begin{array}{c}4 \mathrm{mmol} / \mathrm{L} \text { calcium } / \\
0.5 \mathrm{mmol} / \mathrm{L} \text { oxalate }+ \\
0.25 \mathrm{mmol} / \mathrm{L} \text { trisodium citrate }\end{array}$ & $\begin{array}{c}4 \mathrm{mmol} / \mathrm{L} \text { calcium/ } \\
0.5 \mathrm{mmol} / \mathrm{L} \text { oxalate }+ \\
0.01 \mathrm{~g} / 100 \mathrm{~mL} \mathrm{SGP}\end{array}$ & $P$ \\
\hline$t_{\max }(\min )$ & $8.67 \pm 0.94$ & $13.44 \pm 0.57$ & $14.02 \pm 0.82$ & $\begin{array}{l}P<0.05^{\text {a }} \\
P<0.05^{b}\end{array}$ \\
\hline $\mathrm{S}_{\mathrm{N}}\left(\times 10^{-3} / \mathrm{min}\right)$ & $5.30 \pm 1.23$ & $2.20 \pm 0.36$ & $1.63 \pm 0.28$ & $\begin{array}{l}P<0.05^{\mathrm{a}} \\
P<0.05^{\mathrm{b}}\end{array}$ \\
\hline $\mathrm{S}_{\mathrm{A}}\left(\times 10^{-3} / \mathrm{min}\right)$ & $1.87 \pm 0.62$ & $0.53 \pm 0.19$ & $0.43 \pm 0.05$ & $\begin{array}{l}P<0.05^{\mathrm{a}} \\
P<0.05^{\mathrm{b}}\end{array}$ \\
\hline
\end{tabular}

\footnotetext{
a $4 \mathrm{mmol} / \mathrm{L}$ calcium $/ 0.5 \mathrm{mmol} / \mathrm{L}$ oxalate compared with $4 \mathrm{mmol} / \mathrm{L}$ calcium $/ 0.5 \mathrm{mmol} / \mathrm{L}$ oxalate $+0.25 \mathrm{mmol} / \mathrm{L}$ trisodium citrate; ${ }^{\mathrm{b}} 4 \mathrm{mmol} / \mathrm{L}$ calcium $/ 0.5 \mathrm{mmol} / \mathrm{L}$ oxalate compared with $4 \mathrm{mmol} / \mathrm{L}$ calcium $/ 0.5 \mathrm{mmol} / \mathrm{L}$ oxalate $+0.01 \mathrm{~g} / 100 \mathrm{~mL}$ SGP.
}

\subsection{Effect on Crystal Morphology}

The amount of crystal formation, as estimated from the turbidity of the solution, is shown in Figure 2. Incubating solutions of $\mathrm{Ca}^{2+}$ and $\mathrm{Ox}$ resulted in the formation of $\mathrm{CaOx}$ crystals (Figure 2A) that consisted largely of hexagonal COM. Both SGP $(0.5 \mathrm{mg} / \mathrm{mL})$ and trisodium citrate $(1 \mathrm{mM})$ resulted in the shape changes of $\mathrm{CaOx}$ crystals, as shown in Figure 2B,C; a more rounded polygonal crystals shape. This shape may prevent the formation of kidney stones, because crystals with this shape are more easily excreted in the urine compared with the COM.

Figure 2. The $\mathrm{CaOx}$ crystals, observed under inverted microscope $(100 \times)$, formed in the metastable solution of $\mathrm{CaOx}$ in the absence (A) and the presence of (B) trisodium citrate $(1 \mathrm{mM})(\mathbf{C}) \mathrm{SGP}(0.5 \mathrm{mg} / \mathrm{mL})$.

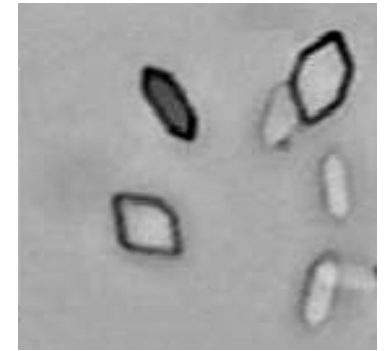

(A)

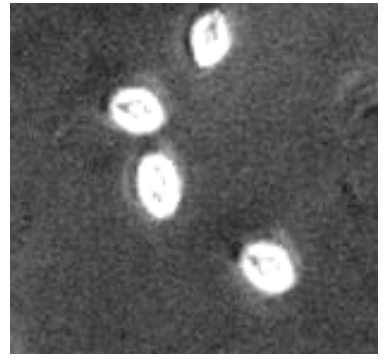

(B)

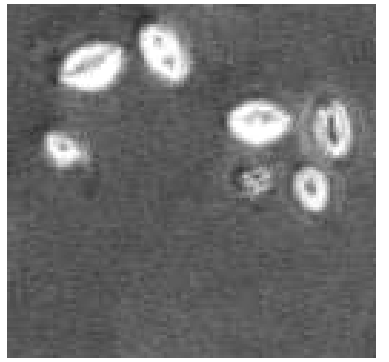

(C)

Microphotography studies verified that SGP resulted in the formation of round $\mathrm{CaOx}$ crystals. $\mathrm{CaOx}$ develops in three different hydrated forms: COM, dehydrate (COD), and trihydrate (COT). $\mathrm{COM}$ is the most thermodynamically stable phase, followed by tetragonal COD and then triclinic COT. COM and COD are the major forms found in most urinary calculi [26,27]. SGP inhibited the growth of COM crystals, prevented the aggregation of COM crystals, and induced the formation of spherical COD crystals. These spherical COD crystals are the thermodynamically less stable phase and have weaker affinity for cell membranes than COM crystals [28]. 


\subsection{Antioxidant Effects of SGP}

The antioxidant properties of SGP are shown in Figures 3-5. Superoxide anion radicals are formed in cellular oxidation reactions, and these radicals can result in the production of hydrogen peroxide and hydroxyl radicals through dismutation and other chemical reactions. Superoxide anions have a longer lifetime and can move over greater distances than other oxygen radicals; hence, they are more damaging [29]. Therefore, the ability to scavenge superoxide anions is an important biological property for a therapeutic compound. The superoxide anion scavenging activity of different concentrations of SGP is shown in Figure 3. The scavenging effects of SGP increased with increasing concentrations; the $\mathrm{IC}_{50}$ was $1.9 \mathrm{mg} / \mathrm{mL}$.

Figure 3. Scavenging of superoxide anion by various concentrations of SGP.

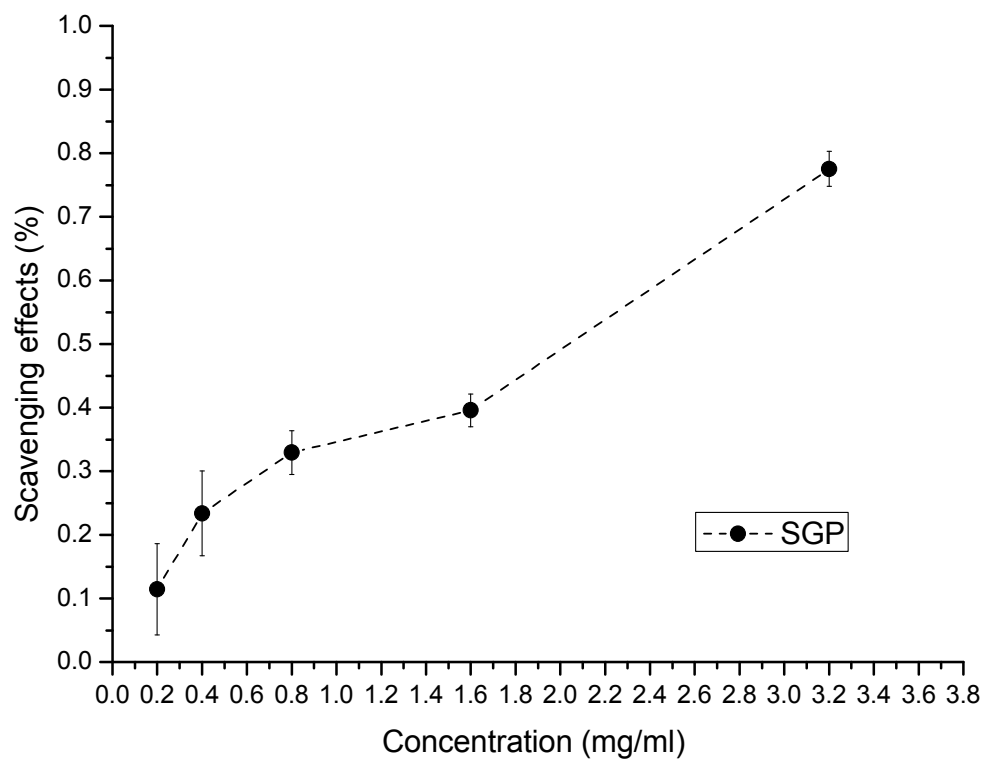

Figure 4. Scavenging of DPPH radical by various concentrations of SGP.

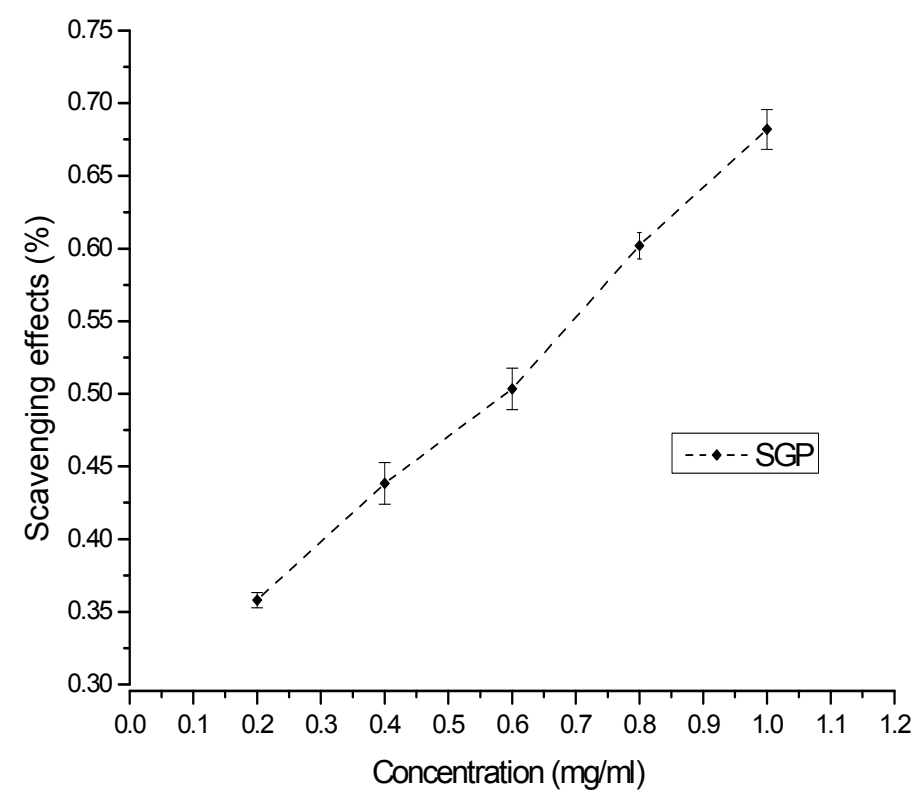


Figure 5. Reducing power of various concentrations of SGP.

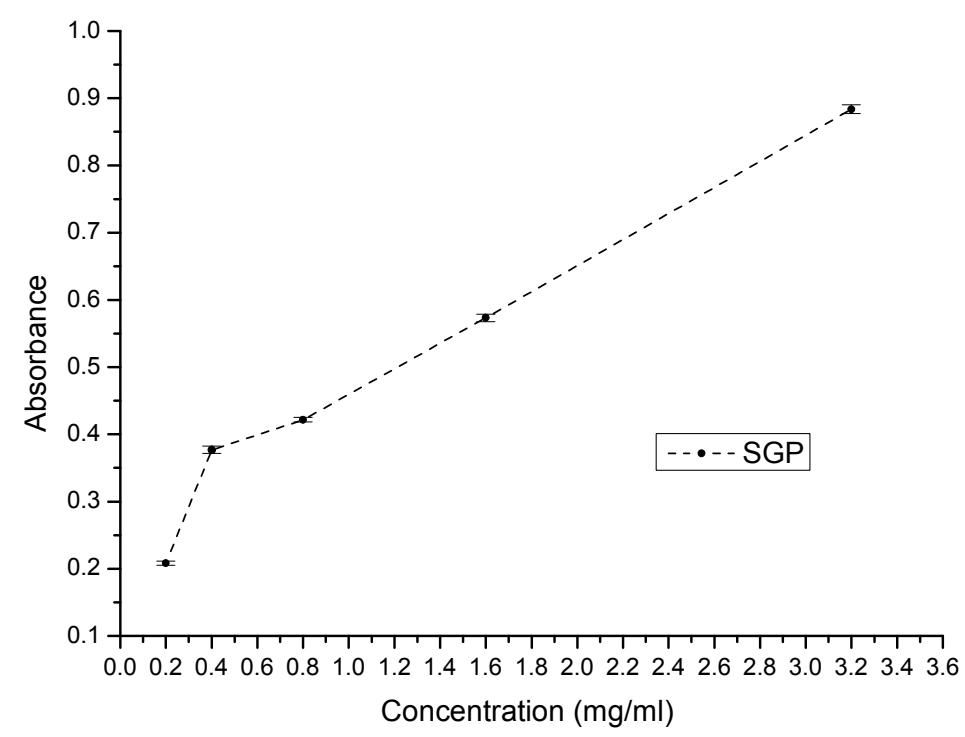

The DPPH free radical is a stable free radical that is widely used as a tool for estimating the free-radical scavenging activities of antioxidants [30]. Free radicals are highly reactive species of atoms or molecules that are unstable because of single or unbalanced electrons. DPPH is a compound with a proton free radical that has a characteristic absorption. The absorption of a DPPH solution decreases significantly in the presence of proton radical scavengers. The scavenging of the DPPH free radical by antioxidants is due to their hydrogen-donating ability [31,32]. The DPPH radical scavenging ability of SGP is shown in Figure 4. The ability to scavenge the DPPH radical increased with increasing concentrations of SGP in a concentration-dependent manner. The $\mathrm{IC}_{50}$ was $0.6 \mathrm{mg} / \mathrm{mL}$.

Reducing power assays are used to evaluate the capacity of natural antioxidants to donate an electron. Natural antioxidants are believed to break free-radical chain reactions by donating an electron or hydrogen atom to free radicals. Therefore, the reducing power of a compound is a significant indicator of its potential antioxidant activity $[33,34]$. The reducing power of SGP is shown in Figure 5. At concentrations of $0.2,0.4,0.8,1.6$ and $3.2 \mathrm{mg} / \mathrm{mL}$, the reducing power of SGP was $0.21,0.37,0.42$, 0.57 and 0.89 , respectively. These results showed that SGP is able to donate electrons, which may be involved in its antioxidant activity.

\section{Experimental Section}

\subsection{Chemicals and Reagents}

Dry S. graminifolium (Turn.) was obtained from Zhuhai, Guangdong Province, China. 1,1-Diphenyl-2-picrylhydrazyl (DPPH) was purchased from Sigma Chemical Co. (St. Louis, MO, USA). All other reagents were of analytical grade.

\subsection{Extraction of Polysaccharides from S. graminifolium and Its Properties}

The polysaccharide extract from $S$. graminifolium (SGP) was prepared as described by Zhuang et al. [35]. Briefly, crude polysaccharides were extracted from the powdered seaweed by chloroform extraction, boiling water extraction, and ethanol precipitation. The degreased seaweed 
powder was incubated in a water bath at $90{ }^{\circ} \mathrm{C}$ for $3 \mathrm{~h}$, and the residue was re-extracted twice and then concentrated to one-third of the original volume at $80{ }^{\circ} \mathrm{C}$, adding $95 \%$ ethanol to the water extract until the ethanol concentration reached $80 \%$. After standing overnight, the mixture was centrifuged at $2775 \mathrm{~g}$ for $15 \mathrm{~min}$. The precipitate containing crude polysaccharides was washed with $95 \%$ ethanol, then with ethyl ether, and finally with acetone. Proteins were removed by adding trichloroacetic acid and centrifuging the mixture at $2775 \mathrm{~g}$ for $15 \mathrm{~min}$, then added some sodium hydroxide in the centrifuged solution, to neutralize the remained TCA, and took dialysis operation for it. The resulting products were concentrated and freeze-dried, then kept it in the refrigerator.

To analyze the constituents of SGP 3 methods were used: the phenol sulfuric acid method for the determination of total sugar content, Folin-Phenol Determination method for protein content, and the barium sulfate turbidimetric method for sulfate content. Furthermore, functional groups of SGP were determined by infrared spectrum (IR).

\subsection{Calcium Oxalate Crystallization Assay}

The effect of SGR on CaOx crystallization was measured spectrophotometrically over 30 min at $620 \mathrm{~nm}$. This assay quantifies crystal nucleation and aggregation in metastable solutions of $\mathrm{Ca}^{2+}$ and Ox. There are three parameters that characterize the crystallization process [36]: first, the maximum increase of optical density (OD) over time, termed $\mathrm{S}_{\mathrm{N}}$, mainly reflects the maximum rate of formation of new particles and thus, represents crystal nucleation. Second, the rate of aggregation, $\mathrm{S}_{\mathrm{A}}$, is derived from the maximum decrease in optical density. Third, the maximum time, $t_{\max }$, is the time at which crystals can neither nucleate nor grow. All three parameters are measurable in the crystallization process of $\mathrm{CaOx}$.

We used linear regression analyses for slope measurements. The percentage inhibition was calculated from the nucleation and aggregation rates, as follows: $\left[1-\left(\mathrm{S}_{\mathrm{Nm}} / \mathrm{S}_{\mathrm{Nc}}\right)\right] \times 100$ for the rate of nucleation and $\left[\left(1-\mathrm{S}_{\mathrm{Am}} / \mathrm{S}_{\mathrm{Ac}}\right)\right] \times 100$, for the rate of aggregation (where $\mathrm{S}_{\mathrm{m}}$ is the slope in the presence of the test material and $\mathrm{S}_{\mathrm{c}}$ is the slope of the control experiment).

$\mathrm{CaOx}$ monohydrate crystallization was achieved using a mixture of calcium chloride $(8 \mathrm{mmol} / \mathrm{L})$ and sodium oxalate $(1 \mathrm{mmol} / \mathrm{L})$, containing $200 \mathrm{mmol} / \mathrm{L}$ sodium chloride and $10 \mathrm{mmol} / \mathrm{L}$ sodium acetate, adjusted to $\mathrm{pH}$ 5.7. The concentrations of compounds in this mixture are close to physiological urinary concentrations. The $\mathrm{CaCl}_{2}$ solution $(1.0 \mathrm{~mL})$ was stirred constantly at $37{ }^{\circ} \mathrm{C}$ both in the absence and presence of different concentrations of the test material or trisodium citrate as the positive control. After obtaining a stable base line, crystallization was induced by the addition of $\mathrm{Na}_{2} \mathrm{C}_{2} \mathrm{O}_{4}$ solution $(1.0 \mathrm{~mL})$ to reach final concentrations of $4 \mathrm{mmol} / \mathrm{L}$ calcium and $0.5 \mathrm{mmol} / \mathrm{L} \mathrm{Ox}$. Modifiers of $\mathrm{CaOx}$ crystallization were compared in assays containing $4 \mathrm{mmol} / \mathrm{L}$ calcium and $0.5 \mathrm{mmol} / \mathrm{L} \mathrm{Ox}$. The change in turbidity over time was measured. All experiments were run in triplicate.

\subsection{Image Analysis of Crystal Morphology}

In this study, we used imaging techniques to observe the size and morphology of the crystals and to verify the effect of incubation with the test material on $\mathrm{CaOx}$ crystal formation. We used stock solutions of $\mathrm{CaCl}_{2}$ and $\mathrm{Na}_{2} \mathrm{C}_{2} \mathrm{O}_{4}$ with compositions similar to those in the kinetic study. Aliquots $(0.5 \mathrm{~mL})$ of $\mathrm{CaCl}_{2}$ solutions containing SGP $(0.5 \mathrm{mg} / \mathrm{mL})$ or trisodium citrate $(1 \mathrm{mmol} / \mathrm{L})$ were added 
to wells in a 24-well plate. To each of the wells, $\mathrm{Na}_{2} \mathrm{C}_{2} \mathrm{O}_{4}$ solution $(0.5 \mathrm{~mL})$ was added to obtain final concentrations of $4.25 \mathrm{mmol} \mathrm{Ca}^{2+}$ and $0.75 \mathrm{mmol} \mathrm{Ox}$ [18]. Each concentration of the test material was prepared in triplicate. The plates were then incubated in a shaking water bath at 90 oscillations/min at $37^{\circ} \mathrm{C}$ for $45 \mathrm{~min}$. Each well was then observed under an inverted microscope (Olympus Corporation, Japan). Crystal morphology was examined in five randomly selected fields at $100 \times$ magnification. Images were captured from different fields. The most representative images are shown in Figure 2.

\subsection{Antioxidant Assays}

\subsubsection{DPPH Assay}

The DPPH scavenging activity of the samples was measured according to the method described by Ye et al. [37]. Briefly, a $0.1 \mathrm{mmol}$ solution of DPPH was prepared in ethanol. Then, a $2.0 \mathrm{~mL}$ aliquot of the DPPH solution $(0.1 \mathrm{mM})$ was incubated with different concentrations of test samples (each $2.0 \mathrm{~mL}$ ). The reaction mixture was shaken well and incubated for $30 \mathrm{~min}$ in the dark, and the absorbance of the resulting solution was measured at $517 \mathrm{~nm}$ against a blank. Measurements were performed at least in triplicate. The percentage of DPPH that was scavenged by the tested extracts was calculated using the following formula:

$$
\text { Scavenging effect }=\left[1-\left(\mathrm{A}_{\text {sample }}-\mathrm{A}_{\text {blank }}\right) / \mathrm{A}_{\text {control }}\right] \times 100 \%
$$

Here, ethanol $(2.0 \mathrm{~mL})$ plus sample solution $(2.0 \mathrm{~mL})$ was used as a blank and $2 \mathrm{~mL}$ DPPH-ethanol solution plus ethanol $(2.0 \mathrm{~mL})$ was used as a negative control.

\subsubsection{Superoxide Radical Scavenging Assay}

The ability of SGP to scavenge superoxide anions was measured using a chemiluminescence method with a BPCL ultra-weak luminescence analyzer (Institute of Biophysics, Beijing, China). The chemiluminescent reaction was conducted in a $\mathrm{Na}_{2} \mathrm{CO}_{3}-\mathrm{NaHCO}_{3}(\mathrm{pH} 10.20,0.5 \mathrm{M}$ ) buffer solution. Scavenging activity of the samples was evaluated according to their quenching effects on the chemiluminescence signal of the luminal-pyrogallol system [38]. The ability to scavenge superoxide anion was calculated as follows:

$$
\text { Scavenging effect }=\left(\mathrm{CL}_{\text {blank }}-\mathrm{CL}_{\text {sample }}\right) / \mathrm{CL}_{\text {blank }} \times 100 \%
$$

Here, $\mathrm{CL}_{\text {blank }}$ and $\mathrm{CL}_{\text {sample }}$ represent chemiluminescence peak areas of the blank group and test group, respectively. The luminous intensity was recorded at 2-s intervals and the total luminous integrated intensity was determined for $150 \mathrm{~s}$.

\subsubsection{Reducing Powers of SGP}

Reducing powers of SGP were evaluated by the method described by Sun et al. [38]. Briefly, an aliquot $(2.0 \mathrm{~mL})$ of each sample (at different concentrations) was mixed with $2.0 \mathrm{~mL}$ phosphate buffer $(0.2 \mathrm{~mol} / \mathrm{L}, \mathrm{pH} 6.6)$ and $2.0 \mathrm{~mL}$ potassium ferricyanide $(1 \% \mathrm{w} / \mathrm{v})$. The reaction mixture was incubated at $50{ }^{\circ} \mathrm{C}$ for $20 \mathrm{~min}$, then $2.5 \mathrm{~mL}$ trichloroacetic acid $(10 \% \mathrm{w} / \mathrm{v})$ was added, and then the mixture was centrifuged at $22.2 \mathrm{~g}$ for $10 \mathrm{~min}$. The supernatant was mixed with $2.5 \mathrm{~mL}$ distilled water and $0.5 \mathrm{~mL}$ 
ferric chloride solution $(0.1 \% \mathrm{w} / \mathrm{v})$, and the absorbance was measured at $700 \mathrm{~nm}$. Increased absorbance of the reaction mixture indicated greater reducing power.

\subsection{Statistical Analysis}

All values shown are means $\pm \mathrm{SD} . P$-values less than 0.05 were regarded as significant. All statistical comparisons between groups were made using one-way analysis of variance with Dunnett's post hoc test or by Student's t-test. Statistical analyses were carried out using Origin 8 software.

\section{Conclusions}

The ability of urine to inhibit $\mathrm{CaOx}$ crystallization is an important mechanism against formation of urinary stones. Various physicochemical techniques, including turbidimetry methods, conductometric and nephelometric titrations, UV-vis and IR spectroscopy techniques, and potential measurements have been used to evaluate crystal formation [8,39]. For the current study, we used a turbidimetry method to induce and monitor crystallization because it is rapid and reproducible, and allows measurements of nucleation, growth, and aggregation of $\mathrm{CaOx}$ crystals [40,41]. We found that SGP inhibited $\mathrm{CaOx}$ crystal nucleation and aggregation at similar rates as trisodium citrate, a well-known inhibitor of $\mathrm{CaOx}$ crystallization that is widely used to prevent urinary stones.

SGP has many negatively charged - OSO3-, - $\mathrm{COO}-$, and - $\mathrm{OH}$ groups, and these anions strongly coordinate with $\mathrm{Ca}^{2+}$ ions [42]. The numerous negatively charged groups of SGP were able to chelate $\mathrm{Ca}^{2+}$ ions, resulting in a rapid increase in the concentration of $\mathrm{Ca}^{2+}$ ions on the surface of the SGP molecules. This resulted in a higher energy interface on the surface of SGP molecules. The adsorption of $\mathrm{Ca}^{2+}$ ions would result in a simultaneous decrease in free $\mathrm{Ca}^{2+}$ ions and an increase in the energy state of $\mathrm{Ca}^{2+}$ ions. Both the high energy interface and high energy state $\mathrm{Ca}^{2+}$ ions would then promote the formation of thermodynamically metastable COD [8].

Our findings indicate that natural substances such as SGP could contribute to the prevention of urinary stones. Sulfated polysaccharides from marine algae possess numerous pharmacological properties, but there is little research on sulfated polysaccharides from $S$. graminifolium. Further studies on natural substances should be carried out to assess their effects on $\mathrm{CaOx}$ crystallization in vivo.

\section{Acknowledgments}

The authors thank Wenhui Wu (Institute of Marine Sciences, Shanghai Ocean University) for assistance with the microscopic analysis. This study was supported by the National 863 Plans Projects of China (2011AA09070109).

\section{References}

1. Hasui, M.; Matsuda, M.; Okutani, K.; Shigeta, S. In vitro antiviral activities of sulfated polysaccharides from a marine microalga (Cochlodinium polykrikoides) against human immunodeficiency virus and other enveloped viruses. Int. J. Biol. Macromol. 1995, 17, 293-297. 
2. Karnjanapratum, S.; You, S. Molecular characteristics of sulfated polysaccharides from Monostroma nitidum and their in vitro anticancer and immunomodulatory activities. Int. J. Biol. Macromol. 2010, 48, 311-318.

3. Rajeswari, A.; Varalakshmi, P. Low molecular weight heparin protection against oxalate-induced oxidative renal insult. Clin. Chim. Acta 2006, 370, 108-114.

4. Wijesekara, I.; Pangestuti, R.; Kim, S.K. Biological activities and potential health benefits of sulfated polysaccharides derived from marine algae. Carbohydr. Polym. 2011, 84, 14-21.

5. Zhang, Z.; Zhang, Q.; Wang, J.; Zhang, H.; Niu, X.; Li, P. Preparation of the different derivatives of the low-molecular-weight porphyran from Porphyra haitanensis and their antioxidant activities in vitro. Int. J. Biol. Macromol. 2009, 45, 22-26.

6. Zhang, Q.; Li, N.; Liu, X.; Zhao, Z.; Li, Z.; Xu, Z. The structure of a sulfated galactan from Porphyra haitanensis and its in vivo antioxidant activity. Carbohydr. Res. 2004, 339, 105-111.

7. Coothan, K.V.; Anthony, J.; Sreenivasan, P.; Preetha, P.V.; Rajaguru, S. Renal peroxidative changes mediated by oxalate: The protective role of fucoidan. Life Sci. 2006, 79, 1789-1795.

8. Das, I.; Gupta, S.K.; Ansari, S.A.; Pandey, V.N.; Rastogi, R.P. In vitro inhibition and dissolution of calcium oxalate by edible plant Trianthema monogyna and pulse Macrotyloma uniflorum extracts. J. Cryst. Growth 2005, 273, 546-554.

9. Basavaraj, D.R.; Biyani, C.S.; Browning, A.J.; Cartledge, J.J. The role of urinary kidney stone inhibitors and promoters in the pathogenesis of calcium containing renal stones. $E A U-E B U$ Update Ser. 2007, 5, 126-136.

10. Bihl, G.; Meyers, A. Recurrent renal stone disease-advances in pathogenesis and clinical management. Lancet 2001, 358, 651-656.

11. Atmani, F.; Khan, S.R. Effects of an extract from Herniaria hirsuta on calcium oxalate crystallization in vitro. BJU Int. 2000, 85, 621-625.

12. Moe, O.W. Kidney stones: Pathophysiology and medical management. Lancet 2006, 367, 333-344.

13. Borghi, L.; Meschi, T.; Guerra, A.; Bergamaschi, E.; Mutti, A.; Novarini, A. Effects of urinary macromolecules on the nucleation of calcium oxalate in idiopathic stone formers and healthy controls. Clin. Chim. Acta 1995, 239, 1-11.

14. Edyvane, K.A.; Hibberd, C.M.; Harnett, R.M.; Marshall, V.R.; Ryall, R.L. Macromolecules inhibit calcium oxalate crystal growth and aggregation in whole human urine. Clin. Chim. Acta 1987, 167, 329-338.

15. Liu, J.; Wang, T.; Chen, J.; Wang, S.; Ye, Z. Decreased inhibitory activity of prothrombin to calcium oxalate crystallization by specific chemical modification of its gamma-carboxyglutamic acid residues. Urology 2006, 67, 201-203.

16. Hackett, R.L.; Shevock, P.N.; Khan, S.R. Madin-Darby ca nine kidney cells are injured by exposure to oxalate and to calcium oxalate crystals. Urol. Res. 1994, 22, 197-203.

17. Koul, H.; Kenington, L.; Honeyman, T.; Jonassen, J.; Menon, M.; Scheid, C.R. Activation of the $c-m y c$ gene mediates the mitogenic effects of Ox in LLC-PK1 cells, a line of renal epithelial cells. Kidney Int. 1996, 50, 1525-1530.

18. Bashir, S.; Gilani, A.H. Antiurolithic effect of Bergenia ligulata rhizome: An explanation of the underlying mechanisms. J. Ethnopharmacol. 2009, 122, 106-116. 
19. Saeed, R.K. Hyperoxaluria-induced oxidative stress and antioxidants for renal protection. Urol. Res. 2005, 33, 349-357.

20. Vanachayangkul, P.; Byer, K.; Khan, S.; Butterweck, V. An aqueous extract of Ammi visnaga fruits and its constituents khellin and visnagin prevent cell damage caused by oxalate in renal epithelial cells. Phytomedicine 2010, 17, 653-658.

21. Srinivasan, S.; Pragasam, V.; Jenita, X.; Kalaiselvi, P.; Muthu, V.; Varalakshmi, P. Oxidative stress in urogenital tuberculosis patients: a predisposing factor for renal stone formation - amelioration by vitamin E supplementation. Clin. Chim. Acta 2004, 350, 57-63.

22. Rodrigo, R.; Rivera, G. Renal damage mediated by oxidative stress: A hypothesis of protective effects of red wine. Free Radic. Biol. Med. 2002, 33, 409-422.

23. Siener, R.; Hesse, A. The effect of different diets on urine composition and the risk of calcium oxalate crystallisation in healthy subjects. Eur. Urol. 2002, 42, 289-296.

24. Wang, J.; Zhang, Q.B.; Zhang, Z.S.; Zhang, H.; Niu, X.Z. Structural studies on a novel fucogalactan sulfate extracted from the brown seaweed Laminaria japonica. Int. J. Biol. Macromol. 2010, 47, 126-131.

25. Samee, H.; Li, Z.X.; Lin, H.; Khalid, J.; Wang, B.P. In vivo study of antiallergenicity of ethanol extracts from Sargassum tenerrimum, Sargassum cervicorne and Sargassum graminifolium Turn. Eur. Food Res. Technol. 2009, 229, 435-441.

26. Ouyang, J.M.; Zheng, H.; Deng, S.P. Simultaneous formation of calcium oxalate (mono-, di-, and trihydrate) induced by potassium tartrate in gelatinous system. J. Cryst. Growth 2006, 293, $118-123$.

27. Yu, J.; Tang, H.; Cheng, B. Influence of PSSS additive and temperature on morphology and phase structures of calcium oxalate. J. Colloid Interface Sci. 2005, 288, 407-411.

28. Liang, M.; Bai, Y.; Huang, L.; Zheng, W.; Liu, J. Inhibition of the crystal growth and aggregation of calcium oxalate by elemental selenium nanoparticles. Colloids Surf. B Biointerfaces 2009, 74, 366-369.

29. Liochev, S.I.; Fridovich, I. The effects of superoxide dismutase on $\mathrm{H}_{2} \mathrm{O}_{2}$ formation. Free Radic. Biol. Med. 2007, 42, 1465-1469.

30. Hu, F.L.; Lu, R.L.; Huang, B.; Ming, L. Free radical scavenging activity of extracts prepared from fresh leaves of selected Chinese medicinal plants. Fitoterapia 2004, 75, 14-23.

31. Bortolomeazzi, R.; Sebastianutto, N.; Toniolo, R.; Pizzariello, A. Comparative evaluation of the antioxidant capacity of smoke flavouring phenols by crocin bleaching inhibition, DPPH radical scavenging and oxidation potential. Food Chem. 2007, 100, 1481-1489.

32. Fagali, N.; Catal, A. Antioxidant activity of conjugated linoleic acid isomers, linoleic acid and its methyl ester determined by photoemission and DPPH techniques. Biophys. Chem. 2008, 137, $56-62$.

33. Hassas-Roudsari, M.; Chang, P.R.; Pegg, R.B.; Tyler, R.T. Antioxidant capacity of bioactives extracted from canola meal by subcritical water, ethanolic and hot water extraction. Food Chem. 2009, 114, 717-726.

34. Wang, H.; Gao, X.D.; Zhou, G.C.; Cai, L.; Yao, W.B. In vitro and in vivo antioxidant activity of aqueous extract from Choerospondias axillaris fruit. Food Chem. 2008, 106, 888-895. 
35. Zhuang, C.; Itoh, H.; Mizuno, T.; Ito, H. Antitumor active fucoidan from the brown seaweed, umitoranoo (Sargassum thunbergii). Biosci. Biotechnol. Biochem. 1995, 59, 563-567.

36. Kulaksizoglu, S.; Sofikerim, M.; Cevik, C. In vitro effect of lemon and orange juices on calcium oxalate crystallization. Int. Urol. Nephrol. 2008, 40, 589-594.

37. Ye, H.; Wang, K.; Zhou, C.; Liu, J.; Zeng, X. Purification, antitumor and antioxidant activities in vitro of polysaccharides from the brown seaweed Sargassum pallidum. Food Chem. 2008, 111, 428-432.

38. Sun, T.; Yao, Q.; Zhou, D.X.; Mao, F. Antioxidant activity of $N$-carboxymethyl chitosan oligosaccharides. Bioorg. Med. Chem. Lett. 2008, 18, 5774-5776.

39. Mushtaq, S.; Siddiqui, A.A.; Naqvi, Z.A.; Rattani, A.; Talati, J.; Palmberg, C.; Shafqat, J. Identification of myeloperoxidase, [alpha]-defensin and calgranulin in calcium oxalate renal stones. Clin. Chim. Acta 2007, 384, 41-47.

40. Hess, B.; Meinhardt, U.; Zipperle, L.; Giovanoli, R.; Jaeger, P. Simultaneous measurements of calcium oxalate crystal nucleation and aggregation: impact of various modifiers. Urol. Res. 1995, 23, 231-238.

41. Gohel, M.D.; Wong, S.P. Chinese herbal medicines and their efficacy in treating renal stones. Urol. Res. 2006, 34, 365-372.

42. Kavanagh, J.P.; Jones, L.; Rao, P.N. Calcium oxalate crystallization kinetics studied by oxalate-induced turbidity in fresh human urine and artificial urine. Clin. Sci. (Lond.) 2000, 98, $151-158$.

Samples Availability: Available from the authors.

(C) 2012 by the authors; licensee MDPI, Basel, Switzerland. This article is an open access article distributed under the terms and conditions of the Creative Commons Attribution license (http://creativecommons.org/licenses/by/3.0/). 